\title{
ÍNDICES DE DESEMPENHO: COMPARAÇÃO DAS ESCOLAS MILITARIZADAS COM AS TRADICIONAIS DE GUARANTÃ DO NORTE/MT
}

\author{
PERFORMANCE INDEXES: COMPARING MILITARIZED SCHOOLS WITH \\ TRADITIONAL ONES IN GUARANTÃ DO NORTE/MT
}

DOI: http://dx.doi.org/10.23926/RPD.2526-2149.2020.v5.n1.p522-543.id636

\section{Krishna Rodrigues de Rosa \\ Doutoranda em Ciência e Tecnologia dos Alimentos (UFSM) \\ Professora no Instituto Federal de Mato Grosso (IFMT/GTA) \\ krrhare@gmail.com}

\section{Ana Paula Teles dos \\ Reis}

Especialista em Gestão

Pública (IFMT/VGD).

Técnica Administrativa

Educacional na Prefeitura de

Peixoto de Azevedo

telesreis@hotmail.com

\section{Antonia Eva}

\section{Rodrigues da Silva}

Especialista em Gestão

Pública (IFMT/VGD)

Técnica Administrativa

Educacional na Prefeitura de Peixoto de Azevedo

evinhagt@hotmail.com

\author{
Alessandra Maria \\ Filippin dos Passos \\ Mestranda em Ciências \\ Ambientais (UNEMAT) \\ alessandraflppn@gmail.com
}

Resumo: A escola deve ser referência de um local seguro e propiciador de conhecimento, em que o aluno possa conhecer seus próximos e a sociedade em que vive. Neste sentido, objetivou-se analisar, neste trabalho, um projeto denominado "Escola Segura", desenvolvido no município de Guarantã do Norte - MT, com o intuito de comparar escolas que implementaram o projeto com outras que não o fizeram. Para tal, foram avaliadas duas escolas militarizadas e duas tradicionais, nos níveis de ensino fundamental e médio, com base no desempenho escolar referente aos anos de 2017, 2018 e 2019/1. Constatou-se diferença significativa apenas nas escolas de ensino médio, contudo, houve um ligeiro progresso nas notas de português e de matemática na escola $\mathrm{B}$, ao passo que o índice do IDEB 2016 da escola A foi maior. Espera-se que o resultado das escolas militarizas, no próximo IDEB e no próximo ENEM, melhorem, já que as notas nas disciplinas avaliadas tiveram o incremento de um ponto após a implementação do projeto.

Palavras-chave: Escola Segura; IDEB; ENEM.

\begin{abstract}
The school should be a reference for a safe and knowledgeable place, where students can get to know their neighbors and the society in which they live. In this sense, the goal of this work was to analyze a project called Escola Segura, developed in of Guarantã do Norte - MT. It was compared schools that implemented the project with others that did not. To this end, two militarized schools and two traditional schools, elementary and high school levels, were evaluated, based on school performance over the years of 2017, 2018 and 2019/1. There was a significant difference only in high schools, however, there was a slight progress in the grades of Portuguese and Mathematics subjects in school B, while the IDEB 2016 index of school A was higher. It is expected that the result of militarized schools in the next IDEB and in the next ENEM will improve, since the grades in the evaluated subjects had an increase of 1.0 point after the implementation of the project.
\end{abstract}

Keywords: School Safety; IDEB; ENEM. 


\section{INTRODUÇÃO}

Anualmente, o Instituto de Pesquisa Econômica Aplicada (IPEA) lança um atlas contendo informações sobre o nível de violência no Brasil, em seus estados e municípios, destacando, também, as estatísticas delimitadas por classe, idade, gênero, entre outros. No ano de 2018, ao demonstrar dados referentes à década de 2006-2016, com ênfase no ano de 2016, o órgão relatou que o país alcançou um número histórico de homicídios, totalizando 62.517, que equivalem a 30,3 mortes para cada 100 mil habitantes. Esse número é 30 vezes maior que a taxa descrita pelo continente europeu, ao passo que, quando se analisa a taxa de violência no grupo de jovens (homens de 15 a 19 anos), verifica-se que ela corresponde a 56,5\% da causa de óbitos entre esse grupo social (CERQUEIRA et al., 2018b).

Ao aprofundar-se no âmbito dos estados, composto por 27 unidades federativas, verifica-se que, entre os estados mais violentos do país, está o Mato Grosso, que ocupa o $11^{\circ}$ lugar, obtendo uma taxa de 35,7 mortes para cada 100 mil habitantes. Além disso, o estado em questão possui 1.180 mortes em número absoluto e uma morte por intervenção policial, contra 1.374 no país todo. Os dez estados mais violentos, em 2016, foram: $1^{\circ}$ Sergipe (taxa de 64,7 mortes para cada 100 mil habitantes), $2^{\circ}$ Rio Grande do Norte, $3^{\circ}$ Alagoas, $4^{\circ}$ Pará, $5^{\circ}$ Amapá, $6^{\circ}$ Pernambuco, $7^{\circ}$ Bahia, $8^{\circ}$ Goiás, $9^{\circ}$ Ceará e $10^{\circ}$ Rio de Janeiro (CERQUEIRA et al., 2018b).

Quando se municipaliza o estado de Mato Grosso, constata-se que, entre os 123 municípios brasileiros responsáveis por 50\% das mortes violentas no país em 2016, três são provenientes desse estado; os municípios são: Várzea Grande $(52,0)$, Rondonópolis $(50,7)$ e Cuiabá (40,8) (CERQUEIRA et al., 2018a). No entanto, o município de Guarantã do Norte, local alvo deste estudo, ocupou, em 2013, o $1.026^{\circ}$ lugar, no ranking nacional, e o $41^{\circ}$ lugar, no ranking estadual de municípios, com número total de 10 óbitos (DEEPASK, 2013). Esse fato não representa um sinal de alerta. Contudo, no que diz respeito à cidade de Altamira, com baixo número de habitantes (32.940 em 2014), pouca idade (emancipação em 1986) (PMSB, 2016), próxima ao estado do Pará $(70 \mathrm{~km})$ e que foi descrita como a oitava cidade mais perigosa do país em 2016 (CERQUEIRA et al., 2018a), deve-se de tomar as rédeas para que a violência não se propague.

Para tal, o Estado é evidenciado como o principal agente promotor de segurança pública. Porém, há muitos desafios para a efetividade dessa ação, visto que a violência vem aumentando e outros atores vêm sendo necessários para desempenharem um papel em relação à segurança pública (LIBERAL et al., 2005). Em relação à segurança escolar, o Brasil implantou políticas 
públicas que visam à redução da violência e à manutenção da ordem em escolas públicas de esferas estaduais e municipais.

Entretanto, os dados disponibilizados a nível mundial reiteram que a violência escolar está longe de se extinguir, ao mesmo tempo em que, em todo o mundo, 20\% dos alunos que frequentam escola rotineiramente sofrem algum tipo de violência todos os anos. Em alguns países, este total é ultrapassado, visto que cerca de 34\% dos estudantes entre 11 e 14 anos afirmam que já sofreram algum tipo de violência, tanto dentro quanto fora da escola, em seu trajeto para casa. Infelizmente, o nosso país está no topo do ranking da violência contra os professores nas escolas, considerando os dados de 34 países desenvolvidos, emergentes e subdesenvolvidos, cujos alunos possuem entre 11 a 16 anos de idade (SILVA, 2018).

O caso está tão grave que, somente no primeiro semestre de 2017, o estado de Mato Grosso registrou um acréscimo de 54\% de ocorrências de crimes dentro do ambiente escolar, quando comparado com o mesmo período do ano anterior. Totalizou, assim, 1.956 registros (contra 1.270 de 2016), dos quais quase 70\% são ligados a furto, ameaça e lesão corporal (SÓ NOTÍCIAS, 2017).

Neste sentido, tendendo a trazer certa ordem e restaurar o respeito ao professor, Elias Belarmino Correia criou, em 2007, um projeto denominado "Escola Segura", cujo objetivo inicial consistia na aplicação prática de medidas de segurança, saúde e meio ambiente, para a adequação do ambiente escolar às normas e à legislação exigidas, e com o intuito de sensibilizar a comunidade escolar sobre a importância da segurança no seu dia a dia.

No estado de Mato Grosso, com foco no combate à violência na escola e em seu entorno, foi instituído, por meio do decreto 1.157 de 2012, publicado em Diário Oficial do Estado em 29/06/2018, o "Programa Escola Segura". Essa é mais uma ação prevista dentro do Plano Estadual de Combate às Drogas, que agregou esforços junto às Secretarias de Educação, de Justiça e Direitos Humanos, e de Segurança Pública. O decreto cria, ainda, a assessoria militar para atuar conjuntamente com a SEDUC, nas ações de enfrentamento à violência, para a promoção de uma cultura de paz. Nesse sentido, o "Programa Escola Segura" atua em consonância às ações da SEDUC que integram o Projeto Paz nas Escolas (NEVES, 2018).

As escolas militarizadas diferem das tradicionais em questão de organização, contudo, continuam a seguir o organograma educacional e a estrutura das escolas públicas, nos níveis de ensino fundamental e médio. Todavia, na escola militarizada, a função das gestões escolar e educacional é transferida para instituições militares - polícia militar - ao passo que a parte 
didático-pedagógica permanece com os professores e demais profissionais da educação (BRASIL, 2020).

Ou seja, nada é modificado em questão de conteúdo programático, mas, sim, na forma como os estudantes e todas as pessoas ligadas diretamente à escola devem se portar. Essa modificação afeta principalmente os elementos concernentes à disciplina, segundo os quais as transgressões são categorizadas em leve, média e grave. São exemplos de transgressões: mascar chiclete nas dependências da escola, comparecer aos trabalhos escolares sem o material necessário e manter unhas fora do padrão (leves); não cortar o cabelo adequadamente, assim como usar barba e bigode, abandonar qualquer atividade recebida para o qual tenha sido escalado e deixar de prestar continência aos militares (médias); e deixar de zelar pelo bom nome do colégio, provocar ou disseminar discórdia entre colegas e faltar com a verdade e/ou utilizar de anonimato para a prática de qualquer transgressão disciplinar (graves) (BERTONI, 2019).

Atualmente o Estado conta com diversas escolas militarizadas, sendo que umas das mais recentes foram aquelas implantadas no município de Guarantã do Norte, cidade limítrofe entre os estados de Mato Grosso e Pará. A prefeitura atual da cidade desempenha um arrojado papel, almejando transformar o município em polo educacional; contudo, registrou um aumento no número de assaltos e da violência nos últimos anos, chocando a população local. Esse fato levou o governador do estado, Pedro Taques, e o secretário-chefe da Casa Civil, José Adolpho, a fazerem uso de reforço da segurança pública do município, por meio da presença do Batalhão de Ronda Extensiva (Rotam) e dos demais grupos que compõem as forças de segurança em Mato Grosso (LIMA, 2017).

No ano de 2018, o município de Guarantã do Norte deu início à implantação das escolas militarizadas, sendo contempladas a Escola Municipal Darcy Ribeiro, a Escola Municipal Sueli Olmira (ambas de ensino fundamental), e Escola Estadual Albert Einstein (de ensino médio). Juntas, essas escolas atendem, diretamente, um grupo de cerca 1.200 alunos de ambos os sexos, na faixa etária de quatro a 17 anos (POLÍCIA MILITAR, 2018). Como o projeto se encontra em fase inicial, é possível questionar: os resultados das escolas tradicionais se aproximam ou se distanciam dos resultados das escolas que aderiram ao "Projeto Escola Segura"? É de grande importância investigar os resultados obtidos até o presente momento, tanto para fortalecer o projeto em si, como também para verificar se realmente existem ou não melhorias concretas nos índices de desempenho escolar após a implementação do projeto.

Este estudo está estruturado em quatro partes. A primeira é a introdução, em que apresentamos os dois modelos de escolas a serem analisados, bem como alguns dados e 
informações relativos ao cenário das escolas do estado. Na sequencia, há o referencial teórico, em que são abordadas questões de violência nas escolas e possíveis ações dos governantes que possam mitigá-las, além de trazer elementos relacionados ao contexto das questões escolares na região de Guarantã do Norte - cidade onde o estudo foi realizado. A terceira parte é composta pela metodologia, em que apresentamos os caminhos, materiais e métodos utilizados para capturar os resultados, que estão disponíveis na quarta parte do estudo.

\section{REFERENCIAL TEÓRICO}

A escola é objeto de desenvolvimento do aluno, visto que objetiva estimular suas habilidades intelectuais e a absorção crítica dos conhecimentos produzidos. Ela deve ser referência de um local seguro e propiciador de conhecimento, em que o aluno possa conhecer seus próximos e a sociedade em que vive (STELKO-PEREIRA; WILLIAMS, 2010).

No Brasil, crianças, jovens e adolescentes são os mais vitimados pela violência. A escola ocupa o terceiro lugar em relação aos locais mais frequentes em que são evidenciados atos violentos (MALTA et al., 2010). A violência escolar se manifesta como uma relação de poder sobre o outro, de forma que a obtenção desse poder caracteriza os meios de violência (VELHO, 2000). Práticas diárias de discriminação, preconceito e a falta de autoridade demonstrada pelos profissionais no âmbito escolar são fatores que relatam a ausência de segurança nas escolas públicas brasileiras (SPOSITO, 2001).

A violência escolar também é caracterizada pela violência praticada pelas estudantes, por meio de xingamentos, vandalismo, agressões físicas ou verbais. Ela pode ocorrer entre alunos e professore e somente entre alunos. São caracterizados como violência escolar, também, os furtos, tanto de materiais da escola, como de objetos pessoais de alunos e dos profissionais escolares (SOUZA, 2012).

Neste sentido, Gonçalves e Sposito (2002), estudando quais possíveis iniciativas públicas auxiliariam na redução da violência escolar, depararam-se com resultados alarmantes. Em se tratando de agressões sofridas por alunos dentro das escolas, o Distrito Federal obteve os maiores índices do país, com 58,6\%; em contrapartida, o estado de Goiás, situado em mesmo território geográfico, alcançou o índice de 8,5\%, sendo o menor constatado no estudo. Em se tratando de agressões sofridas pelos professores, praticadas por alunos, o estado de Mato Grosso demonstrou o maior índice (33\%), ao passo que o estado do Rio de Janeiro, descrito diversas vezes como um dos estados brasileiros de maior violência, relatou o menor número de ocorrências físicas contra os docentes $(1,2 \%)$. 
Dessa forma, a atuação do governo e dos tomadores de decisão em relação a políticas públicas voltadas à segurança escolar devem ser eficientes. Por isso, o estado de Mato Grosso adotou medidas que vão ao encontro do contexto de segurança que deve ser implantado no ambiente escolar, visando à proteção dos profissionais da escola, dos alunos e da sociedade, através da lei 10.473/201. Essa lei foi sancionada pelo governador Pedro Taques e é de autoria do deputado Sebastião Rezende (PSC); ela institui a "Política de Prevenção à Violência contra Profissionais da Educação da Rede de Ensino do Estado de Mato Grosso" (SÓ ESCOLA, 2017) e o "Projeto Escola Segura", desenvolvido pelo $15^{\circ}$ Comando Regional da Polícia Militar. O objetivo do projeto é preparar jovens e adolescentes para um desenvolvimento social saudável e, ao mesmo tempo, resgatar aqueles que estão em condições de vulnerabilidade, ações que são tomadas como as únicas alternativas eficazes para a redução e a extinção da violência entre alunos, e entre alunos e professores.

Neste sentido, a referida lei determina que as medidas de segurança, de proteção e de prevenção de atos de violência e constrangimento aos educadores incluam campanhas educativas na comunidade escolar e na comunidade geral. Prevê, também, afastamento temporário do infrator, conforme a gravidade do ato praticado, e transferência do infrator para outra escola, a juízo das autoridades educacionais (SÓ ESCOLA, 2017). Outro ponto importante é que os pais de alunos menores de idade que agredirem professores da rede pública estadual de Mato Grosso deverão responder pelo ato, assim como o menor de idade e a instituição de ensino (G1, 2017).

No ano de2015, o estado de Goiás aderiu a esse projeto, com a implementação de oito escolas militarizadas no mesmo ano. Em depoimento, um pai e comerciário de 41 anos afirmou que tem duas filhas em escolas da PM e quer colocar a terceira na instituição em 2016, visto que “o nível dessas escolas é muito melhor”. Ele ainda relatou que sua filha Júlia, de 17 anos, diz gostar do Colégio Hugo Ramos, mas reclama da rigidez. Entretanto, o pai afirmou que os alunos têm voz ativa e, toda vez que sua filha reclamou, deram-lhe resposta (BERTONI, 2015).

Já em 2017, na cidade de Campo Grande, no Mato Grosso do Sul, o prefeito Valson relatou que, em dois meses de funcionamento da escola militarizada, os primeiros resultados demonstraram que diminuiu o número de vandalismo, furtos e brigas, dentro das escolas e no raio de 200 metros monitorados pelas equipes. A nota média dada pelos diretores ao programa, no segundo mês de funcionamento, é 8,9 e, segundo Valson, prefeitos de outros municípios buscam informações sobre o programa, demonstrando que o interior também deseja implantar o mesmo sistema nas escolas (NASCIMENTO, 2017). 
Também em 2017, o estado de Roraima anunciou que, no ano seguinte, aumentaria o número de escolas militarizadas de três para 18 e, conforme relatado pelo coronel Elson Paiva e pela diretora Ismência Andrade, a metodologia militar é baseada na disciplina e na hierarquia - dois pilares que sustentam o ensino militar diariamente, fazendo com que os alunos sigam uma rotina pedagógica organizada, em que a permanência é efetiva, em conjunto com a aprendizagem (CHAVES, 2017).

Além disso, mais especificamente no município de Guarantã do Norte (725 quilômetros da capital Cuiabá), três escolas militarizadas foram instauradas no ano de 2018 (duas escolas municipais e uma escola estadual). A implementação se iniciou com a escola municipal de ensino básico, na qual se almejava que o projeto fosse eficaz no auxílio aos professores, aos coordenadores e à direção no desenvolvimento do ensino para os alunos. A principal meta, para os dois primeiros anos, consistia em tornar a escola uma referência, com um nível de ensino elevado (DEAN, 2018). Posteriormente, as ações se estenderam à escola estadual de ensino médio, onde, em uma reunião com pais, responsáveis e professores, o diretor da escola, Ocimar Mezzomo, realizou uma votação para a implantação ou não do "Projeto Escola Segura", obtendo sua aprovação por unanimidade, com 163 votos (PAULO, 2018).

Em setembro de 2019, o Ministério da Educação (MEC) anunciou o "Programa Nacional das Escolas Cívico-Militares" cuja intensão é implementar 216 escolas cívicomilitares no país até 2023. O projeto tem 54 milhões de reais de orçamento para o ano de 2020; cada escola que aderir a ele - de forma voluntária - deverá receber cerca de um milhão de reais para realizar as alterações estruturais necessárias para a implementação do referido programa. Podem participar todos os estados e seus respectivos municípios, desde que atendam ao cronograma estabelecido para cada ente federativo. Contudo, este projeto-piloto do programa destina-se às escolas de ensino regular que têm as etapas de ensino fundamental II e/ou ensino médio (GAUCHAZH, 2019).

O fato de as escolas militarizadas terem sido implantadas no município de Guarantã do Norte recentemente levou a uma investigação dessas escolas e de seus impactos nos índices escolares. Essa investigação foi feita, contrapondo-as com escolas de mesmo nível - municipal e estadual - e de mesma abrangência - ensino fundamental e ensino médio. Seu objetivo consistiu em verificar se as escolas militarizadas realmente desempenham um importante papel na educação e na segurança da sociedade local, tornando-se instituições muito peculiares e proveitosas. Ademais, a investigação possibilita obter informações que podem auxiliar na tomada de decisão para que o projeto prossiga na região, visto que a prefeitura já começou a 
buscar a opinião dos pais e de professores sobre a extensão do projeto no município para o próximo ano. Por isso, ressaltam-se a importância e objetivo deste estudo, com a finalidade de abordar tais questões.

\section{Metodologia}

Este estudo consiste na análise documental do índice de desempenho dos alunos da rede pública de ensino do município de Guarantã do Norte/MT. A análise ocorreu por meio de duas visitas in loco - 09 e 10/2018 e 09 e 10/2019 - nos quatro locais alvos do estudo. Com essas visitas, buscaram-se os dados de aprovação, reprovação, transferência, quantidade de alunos por sala e a média das notas por disciplina, referentes aos anos de 2017, 2018 e 2019/1 de todas as escolas. A partir desses dados, verificou-se que, nas escolas militarizadas, o índice de desempenho é superior ao das escolas tradicionais. Além disso, foram utilizados, na análise, os dados disponíveis no site do Ministério da Educação, principalmente aqueles condizentes à classificação das escolas em relação ao IDEB (Índice de Desenvolvimento da Educação Básica) de 2015 e 2017, e do ENEM (Exame Nacional do Ensino Médio), de 2016, 2017 e 2018.

Dessa forma, foram avaliadas uma escola municipal de ensino fundamental (Escola A) e uma escola estadual de ensino médio (Escola $\mathrm{C}$ ) tidas como tradicionais, mas que não implantaram o "Projeto Escola Segura". Ainda, foram avaliadas uma escola municipal de ensino fundamental (Escola B) e uma escola estadual de ensino médio (Escola D) que implantaram o referido projeto, e que são entendidas como escolas militarizadas.

Nas escolas de ensino fundamental, foi avaliada uma turma de cada série, do sexto ao nono ano; nas escolas de ensino fundamental, avaliou-se, também, uma turma de cada ano, do primeiro ao terceiro. Visando à diminuição de erros do tratamento dos dados, analisaram-se turmas provenientes do mesmo período letivo (matutino ou vespertino) e os resultados obtidos foram submetidos à análise de variância (ANOVA). As médias foram comparadas pelo teste de Qui-quadrado a 5\%, e, os índices, pelo teste de Tukey a 5\% de probabilidade via programa estatístico R versão 3.6.2 (R CORE TEAM, 2019).

\section{Resultados}

Sabe-se que a escola pública, no Brasil, passou por diversas transformações nos últimos trinta anos. Essas transformações exacerbaram-se durante o mandato do presidente Fernando Henrique Cardoso, que instituiu um programa de governo que deliberava que a liberdade de ensino e a expressão de alunos e de professores eram mais importantes do que o conhecimento em si. Além disso, a escola pública brasileira expandiu sem um investimento adequado, num 
processo de "expansão para menos" que culminou no diagnóstico dos setores dominantes de que o país vivia um "apagão educacional". Esse apagão gerou os ditos analfabetos funcionais: alunos e cidadãos que possuem conhecimento para a vida e para o trabalho, mas que, na realidade, não conseguem efetuar operações básicas de matemática ou efetuar leitura e interpretação de texto (GUIMARÃES, 2017).

Guimarães (2017) relata que houve um descaso para com a educação, ao se demonstrar tanto para o discente quanto para o docente que não importa o real conhecimento repassado $\mathrm{e}$ absorvido, mas sim a mera presença do aluno na instituição. Baixaram-se, assim, os índices de crianças e adolescentes fora da escola. Com a posterior implantação da metodologia de Ciclo Seriado, segundo a qual o aluno da rede pública não pode ser reprovado (a não ser perante casos extremos ou pelo não cumprimento da carga horária), agravou-se a falta de estímulo, do professor, para educar, e do aluno, para aprender e para respeitar o seu professor. Isso que gerou um incremento na violência escolar.

Esse tipo de violência aumentou não somente do ponto de vista quantitativo, como também do ponto de vista qualitativo, podendo ser observado em ações cotidianas, como as ameaças e as agressões verbais entre alunos e entre estes e os adultos. Neste sentido, os relatos de professores sobre o desrespeito sofrido durante seu trabalho vêm se tornando quase que corriqueiros. A violência torna o ambiente escolar, na rede pública, algo quase que intragável e, diversas vezes, acaba ocasionando agressões físicas (PAULA e SILVA.; SALLES, 2010).

Essa condição tem gerado uma insatisfação, por parte da sociedade brasileira, que, em resposta, vem cobrando dos políticos uma ação para sanar tal problema. A diminuição da violência depende de uma postura firme e do empenho do corpo docente nas atividades didáticas. É necessário, também, o compromisso dos professores com o seu trabalho e o tratamento não diferenciado entre os alunos de melhores e piores rendimentos escolares. Ainda, deve-se estimular o interesse dos alunos pela escola e pelas tarefas escolares (PAULA e SILVA; SALLES, 2010). Nesse sentido, diversas metodologias de ensino vêm sendo criadas e, imputada neste contexto, está a escolha dos estados brasileiros em implementar as escolas militarizadas (GUIMARÃES, 2017).

Esse novo Modelo Militarizado de Gestão Escolar vêm se apresentando como a solução para a problemática da violência nas escolas e, por conta disso, vêm seduzindo parte da sociedade civil. As propostas oficiais de melhora substancial do rendimento dos alunos, por meio da diminuição do número de reprovações e da introdução da disciplina militar com princípios norteados pela hierarquia, chamam a atenção de uma parte da população que anseia 
por uma educação de qualidade e pela segurança de seus filhos nas escolas (GUIMARÃES, 2017).

Mesmo não havendo diferença significativa entre as escolas A e B, nem nos anos de 2017, 2018 e 2019 em conjunto, tampouco nos anos considerados separadamente (Tabelas 1, 2, 3 e 4), nota-se um ligeiro progresso nas notas das disciplinas de português e de matemática na escola militarizada. Detalhadamente, na disciplina de matemática dos sexto e sétimo anos (Tabelas 1 e 2) e em ambas as disciplinas nos oitavo e nono anos do ensino fundamental (Tabelas 3 e 4), a média da escola militarizada ultrapassou a média da escola tradicional no ano de 2019.

Tabela 1 - Dados dos índices de desempenho das escolas tradicional e militarizada de Guarantã do Norte no $6^{\circ}$ ano do nível fundamental nos anos de 2017, 2018 e 2019

\begin{tabular}{ccccccc}
\multirow{2}{*}{ Índices } & \multicolumn{2}{c}{2017} & \multicolumn{2}{c}{2018} & \multicolumn{2}{c}{2019} \\
\cline { 2 - 7 } & Escola A & Escola B & Escola A & Escola B & Escola A & Escola B \\
\hline Quantidade de alunos & 29 & 34 & 33 & 31 & 32 & 35 \\
Transferidos & 2 & 2 & 4 & 4 & 2 & 7 \\
Aprovados & 27 & 30 & 29 & 27 & NA & NA \\
Reprovados & 0 & 2 & 0 & 0 & NA & NA \\
Nota média em português & 7,3 & 6,4 & 6,8 & 7,4 & 7,4 & 6,8 \\
Nota média em matemática & 7,1 & 6,8 & 6,8 & 7,3 & 6,5 & 7,7 \\
\hline
\end{tabular}

NA = não aplicável, visto não haver informação.

Tabela 2 - Dados dos índices de desempenho das escolas tradicional e militarizada de Guarantã do Norte no $7^{\circ}$ ano do nível fundamental nos anos de 2017, 2018 e 2019

\begin{tabular}{ccccccc}
\multirow{2}{*}{ Índices } & \multicolumn{2}{c}{2017} & \multicolumn{2}{c}{2018} & \multicolumn{2}{c}{2019} \\
\cline { 2 - 7 } & Escola A & Escola B & Escola A & Escola B & Escola A & Escola B \\
\hline Quantidade de alunos & 32 & 29 & 31 & 36 & 32 & 30 \\
Transferidos & 2 & 3 & 0 & 4 & 2 & 2 \\
Aprovados & 30 & 25 & 30 & 30 & NA & NA \\
Reprovados & 0 & 1 & 1 & 2 & NA & NA \\
Nota média em português & 7,2 & 7,3 & 6,8 & 6,2 & 7,6 & 6,0 \\
Nota média em matemática & 7,0 & 6,5 & 6,8 & 6,8 & 6,4 & 7,1 \\
\hline
\end{tabular}

NA = não aplicável, visto não haver informação.

Tabela 3 - Dados dos índices de desempenho das escolas tradicional e militarizada de Guarantã do Norte no $8^{\circ}$ ano do nível fundamental nos anos de 2017, 2018 e 2019

\begin{tabular}{ccccccc}
\multirow{2}{*}{ Índices } & \multicolumn{2}{c}{2017} & \multicolumn{2}{c}{2018} & \multicolumn{2}{c}{2019} \\
\cline { 2 - 7 } & Escola A & Escola B & Escola A & Escola B & Escola A & Escola B \\
\hline Quantidade de alunos & 29 & 30 & 33 & 37 & 32 & 37 \\
Transferidos & 0 & 3 & 3 & 11 & 1 & 5 \\
Aprovados & 29 & 27 & 30 & 24 & NA & NA \\
Reprovados & 0 & 0 & 0 & 2 & NA & NA \\
Nota média em português & 6,3 & 6,8 & 6,8 & 5,9 & 7,1 & 7,3 \\
Nota média em matemática & 6,3 & 6,3 & 7,0 & 6,8 & 6,0 & 7,1 \\
\hline
\end{tabular}

NA = não aplicável, visto não haver informação. 
Na Tabela 4, os índices do nono ano do ensino fundamental entre as escolas avaliadas conservaram-se semelhantes nos três anos, mas, na disciplina de matemática, a escola militarizada obteve maior nota, assim como o IDEB de 2015 - 6,6 para 6,0. Porém, no ano de 2017, o IDEB da escola de ensino fundamental tradicional foi maior do que da escola militarizada, fato que também se estende à nota de aprendizado e à nota Brasil de português e matemática entre as mesmas (Tabela 6).

Tabela 4 - Dados dos índices de desempenho das escolas tradicional e militarizada de Guarantã do Norte no $9^{\circ}$ ano do nível fundamental nos anos de 2017, 2018 e 2019

\begin{tabular}{ccccccc}
\multirow{2}{*}{ Índices } & \multicolumn{2}{c}{2017} & \multicolumn{2}{c}{2018} & \multicolumn{2}{c}{2019} \\
\cline { 2 - 7 } & Escola A & Escola B & Escola A & Escola B & Escola A & Escola B \\
\hline Quantidade de alunos & 27 & 31 & 35 & 44 & 33 & 35 \\
Transferidos & 3 & 3 & 9 & 12 & 1 & 8 \\
Aprovados & 24 & 28 & 26 & 32 & NA & NA \\
Reprovados & 0 & 0 & 0 & 0 & NA & NA \\
Nota média em português & 6,8 & 6,6 & 6,8 & 6,2 & 7,3 & 7,5 \\
Nota média em matemática & 5,5 & 6,0 & 6,1 & 6,8 & 6,6 & 6,9 \\
IDEB (2015 - 2017 - 2019) & 6,0 & 6,6 & 6,2 & 5,5 & NA & NA \\
\hline
\end{tabular}

NA = não aplicável, visto não haver informação.

Finalizando as escolas de ensino fundamental, a Tabela 5 mostra que, pelo QEDU, no que tange à taxa de aprovação, no ano de 2016, somente o sex to ano da escola tradicional obteve maior valor, enquanto os sétimo e oitavo anos da escola militarizada foram melhores. No que diz respeito a 2017, não houve diferença significativa entre os três anos avaliados, entretanto, a escola tradicional conseguiu progredir ao mesmo tempo em que a escola militarizada decresceu no sétimo ano.

Tabela 5 - Taxa de aprovação das escolas tradicional e militarizada de nível fundamental de Guarantã do Norte do $6^{\circ}$ ao $8^{\circ}$ ano segundo o QEDU (2016) e QEDU (2017)

\begin{tabular}{ccccccc} 
& \multicolumn{3}{c}{2016} & \multicolumn{3}{c}{2017} \\
\cline { 2 - 6 } Escola & \multicolumn{3}{c}{ Taxa de aprovação $(\%)$} & \multicolumn{3}{c}{ Taxa de aprovação $(\%)$} \\
\cline { 2 - 6 } & $6^{\mathrm{o}}$ ano & $7^{\mathrm{o}}$ ano & $8^{\mathrm{o}}$ ano & $6^{\mathrm{o}}$ ano & $7^{\mathrm{o}}$ ano & $8^{\mathrm{o}}$ ano \\
\hline A & $96,5^{\mathrm{a}}$ & $96,2^{\mathrm{b}}$ & $98,2^{\mathrm{b}}$ & $96,6^{\mathrm{a}}$ & $96,5^{\mathrm{a}}$ & $100^{\mathrm{a}}$ \\
$\mathrm{B}$ & $86,2^{\mathrm{b}}$ & $100^{\mathrm{a}}$ & $100^{\mathrm{a}}$ & $93,8^{\mathrm{a}}$ & $96,4^{\mathrm{a}}$ & $100^{\mathrm{a}}$ \\
\hline
\end{tabular}

*Médias seguidas pela mesma letra, na coluna, não diferem entre si pelo teste de Tukey ( $\mathrm{p} \leq 0,05)$. 
Tabela 6 - Dados dos índices de desempenho das escolas tradicional e militarizada de nível fundamental de Guarantã do Norte do $9^{\circ}$ ano segundo o QEDU (2016) e QEDU (2017)

\begin{tabular}{ccccc}
\multirow{2}{*}{ Índices } & \multicolumn{2}{c}{2016} & \multicolumn{2}{c}{2017} \\
\cline { 2 - 5 } & Escola A & Escola B & Escola A & Escola B \\
\hline Fluxo & $0,98^{\mathrm{a}}$ & $0,91^{\mathrm{b}}$ & $0,98^{\mathrm{a}}$ & $0,97^{\mathrm{a}}$ \\
Taxa de aprovação (\%) & 98,2 & $\mathrm{NA}$ & $100^{\mathrm{a}}$ & $100^{\mathrm{a}}$ \\
Taxa de reprovação (\%) & $2,7^{\mathrm{b}}$ & $5,0^{\mathrm{a}}$ & $\mathrm{NA}$ & NA \\
Aprendizado & 6,06 & $\mathrm{NA}$ & $6,36^{\mathrm{a}}$ & $5,59^{\mathrm{b}}$ \\
Nota Brasil - Português & 281,83 & $\mathrm{NA}$ & $287,57^{\mathrm{a}}$ & $267,89^{\mathrm{b}}$ \\
Nota Brasil - Matemática & 282,06 & NA & $293,91^{\mathrm{a}}$ & $267,78^{\mathrm{b}}$ \\
\hline
\end{tabular}

\section{NA = não aplicável, visto não haver informação.}

*Médias seguidas pela mesma letra, na linha, não diferem entre si pelo teste de Tukey $(\mathrm{p} \leq 0,05)$.

Pensando nas escolas de ensino médio, constatou-se que há uma diferença significativa entre as escolas C e D, nos anos de 2017, 2018 e 2019 (Tabelas 7, 8 e 9). Essa diferença é ainda mais evidente quando se compara o ano de 2019 separadamente: a escola militarizada teve um desenvolvimento muito além da escola tradicional, demonstrando o progresso que pode ser aferido a partir da implantação do "Projeto Escola Segura".

Avaliando-se as escolas C e D por série escolar, verificou-se que, no primeiro ano do nível médio, a escola militarizada obteve nota média superior em quase todas as disciplinas, sendo que em filosofia, língua estrangeira (inglês), língua portuguesa, arte, matemática e química, tal condição foi observada em todos os anos avaliados (Tabela 7). Em compensação, no ano de 2018, a escola militarizada diminuiu seu índice em geografia, educação física, língua portuguesa, arte e matemática.

Tabela 7 - Média dos índices de desempenho por turma das escolas tradicional e militarizada de Guarantã do Norte no $1^{\circ}$ ano do nível médio referente aos anos de 2017, 2018 e 2019

\begin{tabular}{ccccccc}
\multirow{2}{*}{ Índices } & \multicolumn{2}{c}{2017} & \multicolumn{2}{c}{2018} & \multicolumn{2}{c}{2019} \\
\cline { 2 - 7 } & Escola C & Escola D & Escola C & Escola D & Escola C & Escola D \\
\hline Quantidade de alunos & 32 & 58 & 35 & 45 & 26 & 58 \\
Transferidos & 5 & 14 & 15 & 11 & 11 & 20 \\
Aprovados & 16 & 30 & 14 & 29 & NA & NA \\
Reprovados & 11 & 14 & 6 & 3 & NA & NA \\
Nota em Filosofia & 5,2 & 5,7 & 6,8 & 7,7 & 6 & 7,9 \\
Nota em Geografia & 6,2 & 6,9 & 6,9 & 6,5 & 6,1 & 7,3 \\
Nota em História & 6,0 & 5,9 & 7,5 & 6,1 & 5,9 & 6,6 \\
Nota em Sociologia & 6,4 & 4,9 & 6,8 & 6,9 & 6,3 & 7,2 \\
Nota em Educação física & 7,0 & 7,2 & 7,5 & 7,4 & 6,8 & 7,5 \\
Nota em Língua estrangeira & 5,2 & 6,0 & 5,7 & 6,3 & 5,2 & 7,4 \\
Nota em Língua portuguesa & 4,7 & 5,6 & 5,8 & 7,1 & 5,8 & 6,5 \\
Nota em Arte & 5,5 & 5,7 & 6,5 & 7,7 & 6,3 & 6,7 \\
Nota em Matemática & 4,8 & 5,7 & 6,1 & 7,3 & 4,7 & 6,8 \\
Nota em Biologia & 5,6 & 6,1 & 6,6 & 6,4 & 5,2 & 9,0 \\
Nota em Física & 5,7 & 5,5 & 7,8 & 6,0 & 5,2 & 7,7 \\
Nota em Química & 5,4 & 6,0 & 6,4 & 6,9 & 5,1 & 7,0 \\
\hline
\end{tabular}

NA = não aplicável, visto não haver informação. 
Segundo os dados do segundo ano do ensino médio, tem-se, na Tabela 8, que em todos os anos avaliados a nota média da escola militarizada foi superior à tradicional, nas disciplinas de filosofia, língua estrangeira (inglês), biologia, física e química. Entretanto, enfrentou uma redução no ano de 2019, nas disciplinas de geografia, sociologia, educação física, língua portuguesa e arte, destacando que ainda há muito por ser melhorado na escola $\mathrm{D}$.

Tabela 8 - Média dos índices de desempenho por turma das escolas tradicional e militarizada de Guarantã do Norte no $2^{\circ}$ ano do nível médio referente aos anos de 2017, 2018 e 2019

\begin{tabular}{ccccccc} 
Índices & \multicolumn{2}{c}{2017} & \multicolumn{2}{c}{2018} & \multicolumn{2}{c}{2019} \\
\cline { 2 - 7 } & Escola C & Escola D & Escola C & Escola D & Escola C & Escola D \\
\hline Quantidade de alunos & 27 & 41 & 31 & 44 & 23 & 45 \\
Transferidos & 11 & 5 & 13 & 11 & 6 & 14 \\
Aprovados & 14 & 31 & 15 & 32 & NA & NA \\
Reprovados & 2 & 5 & 3 & 1 & NA & NA \\
Nota em Filosofia & 6,4 & 7,2 & 7,4 & 8,5 & 6,2 & 8,0 \\
Nota em Geografia & 7,5 & 7 & 8 & 7,0 & 8,2 & 7,2 \\
Nota em História & 7,4 & 7,7 & 8,3 & 7,2 & 6,7 & 7,2 \\
Nota em Sociologia & 7,1 & 6,9 & 7,3 & 8,0 & 7,0 & 7,2 \\
Nota em Educação física & 7,4 & 7,1 & 7,7 & 8,5 & 7,8 & 7,1 \\
Nota em Língua estrangeira & 7,1 & 7,4 & 6,1 & 7,7 & 5,9 & 7,5 \\
Nota em Língua portuguesa & 6,1 & 7,4 & 6,4 & 7,5 & 7,0 & 6,6 \\
Nota em Arte & 7,6 & 6,9 & 7,5 & 8,9 & 7,6 & 6,9 \\
Nota em Matemática & 6,8 & 6,5 & 6,8 & 7,6 & 6,1 & 7,4 \\
Nota em Biologia & 7,3 & 7,5 & 6,7 & 7,6 & 7,3 & 8,2 \\
Nota em Física & 6,3 & 7,7 & 6,6 & 7,2 & 6,8 & 7,1 \\
Nota em Química & 6,7 & 6,8 & 6,6 & 7,8 & 5,3 & 7,3 \\
\hline
\end{tabular}

NA = não aplicável, visto não haver informação.

Trabalhando-se com os dados do terceiro ano do ensino médio, percebe-se, pela Tabela 9, que, além de possuir maior número de alunos por sala (como já verificado anteriormente), a escola militarizada conta com maior índice de alunos transferidos. Tal disparidade pode ocorrer em razão da dificuldade dos alunos em prosseguirem em uma escola cuja metodologia de trabalho foi alterada, com a instauração do "Projeto Escola Segura". Nesta perspectiva, percebeu-se que a escola militarizada obteve seus piores índices na série em questão, mesmo havendo melhorias concretas em algumas disciplinas, como língua estrangeira (inglês) e língua portuguesa. Ela obteve, também, as maiores médias no ano de 2019 em língua estrangeira (inglês), física, química e matemática, o que transpassa a dificuldade da escola em superar índices muito baixos, em um momento anterior à implementação do "Projeto Escola Segura". 
Tabela 9 - Média dos índices de desempenho por turma das escolas tradicional e militarizada de Guarantã do Norte no $3^{\circ}$ ano do nível médio referente aos anos de 2017, 2018 e 2019

\begin{tabular}{ccccccc}
\multirow{2}{*}{ Índices } & \multicolumn{3}{c}{2017} & \multicolumn{2}{c}{2018} & \multicolumn{2}{c}{2019} \\
\cline { 2 - 7 } & Escola C & Escola D & Escola C & Escola D & Escola C & Escola D \\
\hline Quantidade de alunos & 21 & 36 & 10 & 38 & 20 & 42 \\
Transferidos & 8 & 18 & 2 & 6 & 2 & 15 \\
Aprovados & 12 & 17 & 8 & 32 & NA & NA \\
Reprovados & 1 & 1 & 0 & 0 & NA & NA \\
Nota em Filosofia & 6,7 & 7,0 & 8,3 & 8,4 & 7,8 & 6,4 \\
Nota em Geografia & 8,1 & 6,8 & 9,3 & 7,1 & 8,3 & 6,6 \\
Nota em História & 7,5 & 7,6 & 8,7 & 8,4 & 7,2 & 7,2 \\
Nota em Sociologia & 8,0 & 7,4 & 8,8 & 8,4 & 7,3 & 6,8 \\
Nota em Educação física & 8,3 & 7,6 & 8,8 & 8,7 & 8,4 & 8,1 \\
Nota em Língua estrangeira & 7,2 & 7,8 & 7,1 & 8,3 & 6,3 & 7,3 \\
Nota em Língua portuguesa & 6,6 & 7,4 & 7,4 & 7,5 & 7 & 7,0 \\
Nota em Arte & 7,8 & 7,1 & 7,3 & 9,2 & 7,6 & 7,3 \\
Nota em Matemática & 7,7 & 6,8 & 7,6 & 7,7 & 6,2 & 7,1 \\
Nota em Biologia & 7,2 & 7,2 & 8,6 & 8,1 & 7,3 & 6,4 \\
Nota em Física & 6,8 & 6,6 & 7,6 & 7,7 & 6,1 & 6,5 \\
Nota em Química & 6,9 & 6,7 & 7,8 & 7,8 & 6,0 & 6,7 \\
\hline
\end{tabular}

NA = não aplicável, visto não haver informação.

Encerrando com os dados da Tabela 10 que apresentam os índices de desempenho no ENEM, em 2016, 2017 e 2018, das escolas de ensino médio tradicional e militarizada de Guarantã do Norte, verificou-se o incremento da participação dos alunos nas duas escolas. Entretanto, a escola militarizada obteve, sempre, maior conscientização; apesar disso, as notas nas mesmas áreas - tanto entre a mesma escola, como na comparação dos dois sistemas - não foram lineares. A escola militarizada aperfeiçoou suas notas, em 2017 e 2018, em quase todas as áreas (ciências humanas, ciências da natureza, linguagens, matemática e redação), perdendo para a escola tradicional somente em ciências da natureza. Contudo, tais dados ressaltam a evolução do ensino na escola militarizada com o passar dos anos, ao passo que a escola tradicional é vista de forma estagnada.

Tabela 10 - Dados dos índices de desempenho no ENEM das escolas tradicional e militarizada de nível médio de Guarantã do Norte segundo o QEDU 2016, 2017 e 2018

\begin{tabular}{ccccccc}
\multirow{2}{*}{ Índices } & \multicolumn{2}{c}{2016} & \multicolumn{2}{c}{2017} & \multicolumn{2}{c}{2018} \\
\cline { 2 - 7 } & Escola C & Escola D & Escola C & Escola D & Escola C & Escola D \\
\hline Participação (\%) & $59^{\mathrm{b}}$ & $64^{\mathrm{a}}$ & $40^{\mathrm{b}}$ & $59^{\mathrm{a}}$ & $27^{\mathrm{b}}$ & $48^{\mathrm{a}}$ \\
Ciências humanas & $528^{\mathrm{a}}$ & $522^{\mathrm{a}}$ & $482^{\mathrm{b}}$ & $519^{\mathrm{a}}$ & $564^{\mathrm{a}}$ & $563^{\mathrm{a}}$ \\
Ciências da natureza & $477^{\mathrm{a}}$ & $477^{\mathrm{a}}$ & $502^{\mathrm{a}}$ & $486^{\mathrm{b}}$ & $470^{\mathrm{b}}$ & $491^{\mathrm{a}}$ \\
Linguagens & $516^{\mathrm{a}}$ & $495^{\mathrm{b}}$ & $478^{\mathrm{b}}$ & $495^{\mathrm{a}}$ & $508^{\mathrm{b}}$ & $521^{\mathrm{a}}$ \\
Matemática & $479^{\mathrm{a}}$ & $464^{\mathrm{b}}$ & $464^{\mathrm{b}}$ & $481^{\mathrm{a}}$ & $520^{\mathrm{b}}$ & $530^{\mathrm{a}}$ \\
Redação & $489^{\mathrm{a}}$ & $484^{\mathrm{a}}$ & $429^{\mathrm{b}}$ & $520^{\mathrm{a}}$ & $412^{\mathrm{b}}$ & $485^{\mathrm{a}}$ \\
\hline
\end{tabular}

*Médias seguidas pela mesma letra, na linha em mesmo ano, não diferem entre si pelo teste de Tukey ( $\mathrm{p} \leq 0,05)$. 
As escolas são alicerçadas pelos Colégios Militares do Brasil, que estabelecem que a proposta pedagógica esteja assentada nos valores cultuados pelo Exército Brasileiro, por meio de várias estratégias; entre elas, há as seguintes: formar o cidadão por meio do despertar da consciência política destituída de viés ideológico, com oferecimento de palestras e eleições nos grêmios; ministrar educação básica de qualidade aos filhos de militares e civis; promover a educação ambiental; promover a ampliação de alunos nas carreiras militares; projetar a imagem do Exército Brasileiro junto à opinião pública e observar e cultuar as tradições, a memória e os valores do Exército Brasileiro (DURKHEIM, 2008). Essas escolas militarizadas vêm se desenvolvendo, exibindo melhorias nos índices de evasão, distorção idade-série e nas avaliações externas. Contudo, por serem frutos do anseio da parte conservadora da comunidade brasileira, não foram concebidas para serem universalizadas (GUIMARÃES, 2017).

Todavia, Hilário e Conceição (2017), ao analisarem um colégio militar de ensino fundamental do sexto ao nono ano, da cidade de Arrais - TO, evidenciaram que, durante os primeiros sete meses de implantação do colégio, os resultados escolares foram positivos. Isso demonstra que a hierarquia atrelada à disciplina está condicionada ao exercício e à aceitação dos procedimentos apresentados, alcançando o aprendizado através da conduta e do consenso dos alunos em relação ao respeito às regras e às normas. Propicia-se, dessa forma, um ambiente transformador nas esferas sociais, políticas e produtivas, moldando o jovem e tendo como resultado um cidadão crítico e consciente de seus direitos e deveres, capacitado para enfrentar os desafios impostos.

Figueira (2011), durante o desenvolvimento do seu projeto de doutorado, cuja base veio da análise entre forças armadas e ensino pelo Colégio Militar de Campo Grande, nos anos de 1993-2010, constatou que, em 2009, o colégio apresentou ótima classificação no Índice de Desenvolvimento da Educação Básica ao se avaliarem as séries finais do ensino fundamental (quinta a oitava). No estado de Mato Grosso do Sul, apenas três instituições públicas tiveram boa pontuação; uma delas foi o referido colégio, que alcançou a melhor nota e ficou entre as cinco melhores instituições do país, ao registrar nota média de 7,1 , enquanto que a do estado ficou em 6,4.

No entanto, a recente implantação da escola militarizada no município de Guarantã do Norte, mesmo já sinalizando bons índices escolares provenientes do "Projeto Escola Segura", tem como uma das preocupações a alta taxa de transferência gerada. Tal condição é parcialmente explicada por Rivlin (2003), ao preconizar que as experiências de se movimentar 
através dos ambientes da vida diária são integradas em uma série de lugares e eventos, alguns dos quais são mais estimulantes do que outros.

Isso pressupõe que "a pessoa tem qualidades ambientais tanto quanto características psicológicas individuais" (ITTELSON et al., 1974), ou seja, as pessoas fazem parte do seu ambiente, o qual pode lhe trazer um retorno cíclico que é passível de determinação. Por assim dizer, cada pessoa presente em um local contribui para o que está acontecendo ali, mesmo sendo silenciosa e/ou passiva, visto que ela ocupa espaço neste ambiente; mesmo não parecendo, ela se faz presente na vida de todos que partilham dele. Esse fato é facilmente compreendido pelos professores que adaptam a sua dinâmica de ensino de acordo com o ânimo de seus alunos, fazendo sentir que a ausência de apenas um estudante acarreta impacto aos demais.

Neste sentido, quando um aluno, mesmo presente em sala, acaba por não interagir ou até mesmo atrapalha o andamento da aula, ele modifica a atmosfera e as atividades. Entretanto, como o ambiente da escola militarizada não é passível de flexibilização, então, ou o estudante se ajusta e faz parte do todo ou ele simplesmente não se sente integrado e acaba por optar por uma nova escola. Porém, mesmo com tantas dificuldades, o "Projeto Escola Segura", por via das escolas militarizadas do município de Guarantã do Norte, obteve alcance não somente na melhoria do desempenho dos alunos envolvidos, mas também agraciou toda a comunidade local, ao ponto que extrapolou os muros da escola e atingiu a cidade como um todo, diminuindo o índice de violência contra e proferida por menores de idade.

Tal condição foi confirmada por Silva et al. (2018), que estudaram o desenvolvimento do "Projeto Escola Segura" no referido município comparando, os dados de atos disciplinares das escolas militarizadas avaliadas neste estudo, assim como chamadas via 190 e boletins de ocorrência policial militar nos períodos de março a setembro de 2017, e de março a setembro de 2018. Os autores em questão verificaram uma redução de 52,63\% de registros de ocorrências de violência dentro das escolas a partir da implementação do projeto, ao compararem os períodos supracitados. Esses dados são provenientes de atos disciplinares como: descumprimento de regras do regulamento escolar, vias de fato, atrito verbal, ameaça, assédio moral contra o professor, bullying, porte de arma branca e desacato contra o professor (SILVA et al., 2018).

Além disso, Silva et al. (2018) também constataram redução no número de boletins de ocorrência envolvendo menores de idade, no município de Guarantã do Norte, no período pós implantação das escolas militarizadas. Houve a diminuição de $34 \%$ no total dos atos infracionais, sendo estes: furto, tráfico de drogas, uso ilícito de drogas, lesão corporal, vias de 
fato, adulteração de características de arma de fogo, porte ilegal de arma de fogo, disparo de arma de fogo, receptação, perturbação do sossego público, dano, adulteração de características de veículo, dirigir sem carteira nacional de habilitação, conduzir veículo sob influência de álcool, direção perigosa de veículo, ameaça, naturezas diversas, apoio assistencial/conselho tutelar, desacato, resistência à prisão e tentativa de homicídio. Este último foi o que obteve maior índice de redução, tanto em números de frequência quanto em quantidade de menores infratores envolvidos em furto - $10,5 \%$ e $89,5 \%$, respectivamente.

Entretanto, nem tudo são flores. Existem relatos de abuso de autoridade e cerceamento da liberdade de expressão educacional de professores e alunos, assim como muitos temem a presença ativa do armamento por conta dos policiais militares em exercício nas escolas militarizadas (SAMPAIO, 2019). Quão verídicas e significativas são tais descrições no âmbito da totalidade das escolas militarizadas? Cabe uma pesquisa séria, completa e não tendenciosa para averiguar essas informações e, deste modo, apoiar ou não o Programa Nacional das Escolas Cívico-Militares no país.

Em se tratando das experiências vividas durante a realização deste estudo, ratificamos que, no município de Guarantã do Norte, não houve nenhum relato negativo concernente às escolas militarizadas. Pelo contrário, a procura por vagas aumentou tanto, que os pais fazem plantão junto ao site da secretaria de educação municipal, visando a garantir o estudo do filho em tais locais. Isso nos faz acreditar que a escola militarizada é um bom modelo educacional de ensino e que beneficiará direta e indiretamente a sociedade local.

\section{CONSIDERAÇões FinAIS}

Mesmo não havendo outros trabalhos para se comparar, os dados obtidos neste estudo demonstram que a escola militarizada, quando bem inserida na sociedade, pode, sim, expressar melhorias nos índices de desempenho escolar, principalmente quando se trata de escolas que anteriormente possuíam baixos índices. Isso faz com que o nível educacional de uma cidade como, neste caso, Guarantã do Norte, venha aumentar, com o desenrolar do "Projeto Escola Segura".

Além disso, a resposta da comunidade escolar (dos pais e da sociedade guarantanhense em si) ao referido projeto foi bastante positiva, sinalizando que, nos próximos anos, mais escolas devam aderir ao mesmo. Ademais, a comunidade vem balizando municípios próximos para que também implementem o projeto. 
De antemão, espera-se que o resultado das escolas militarizadas no próximo IDEB e no próximo ENEM melhore, já que as notas nas disciplinas aqui avaliadas tiveram, em sua maioria, o incremento de um ponto, de 2017 para 2019/1, ou seja, em um momento posterior à implantação do projeto.

\section{Agradecimentos}

Em especial ao professor Ednei Isidoro de Almeida (IFMT ALF), pela orientação durante a organização e execução do estudo, e ao professor Edgar Nascimento (IFMT BLV), pelo apoio total com a análise estatística. E a todas as escolas avaliadas, por prontamente disponibilizarem os dados, fazendo-o da maneira mais fácil e rápida possível.

\section{REFERÊNCIAS}

AMPLITUDE NEWS. Projeto 'Escola Segura' da Polícia Militar é implantado na Escola Darcy Ribeiro em Guarantã do Norte, 2018. Disponível em: http://www.amplitudenews.com.br/noticia/3389/projeto-escola-segura-da-policia-militar-eimplantado-na-escola-darcy-ribeiro-em-guaranta-do-norte. Acesso em: 07 jul. 2018.

BERTONI, Estêvão. Cresce no Brasil o número de escolas básicas públicas geridas pela PM, 2015. Disponível em: https://www1.folha.uol.com.br/educacao/2015/08/1666631-cresceno-brasil-o-numero-de-escolas-basicas-publicas-geridas-pela-pm.shtml. Acesso em: 01 jul. 2018.

BERTONI, Estêvão. O que são e como funcionam as escolas militarizadas, 2019. Disponível em: https://www.nexojornal.com.br/expresso/2019/02/27/O-que-s\%C3\%A3o-ecomo-funcionam-as-escolas-militarizadas. Acesso em: 03 abr. 2020.

BRASIL. Ministério da Educação (MEC). O que é o Programa Nacional das Escolas Cívico-Militares? 2020. Disponível em: http://escolacivicomilitar.mec.gov.br/18-oprograma. Acesso em: 03 abr. 2020.

CHAVES, Alan. Governo anuncia implantação de ensino militarizado em mais 15 escolas de Roraima em 2018, 2017. Disponível em: https://g1.globo.com/rr/roraima/noticia/governoanuncia-implantacao-de-ensino-militarizado-em-mais-15-escolas-de-roraima-em-2018.ghtml. Acesso em: 01 jul. 2018.

CERQUEIRA, Daniel; LIMA, Renato Sérgio de; BUENO, Samira; COELHO, Danilo; ALVES, Paloma Palmieri; REIS, Milena; MERIAN, Filipe. Atlas da violência 2018 Políticas públicas e retratos dos municípios brasileiros. Rio de Janeiro: IPEA e FBSP, 2018a. 37p. Disponível em: http://www.ipea.gov.br/atlasviolencia/download/10/atlasmunicipio. Acesso em: 20 jan. 2019.

CERQUEIRA, Daniel; LIMA, Renato Sérgio; BUENO, Samira; NEME, Cristina; FERREIRA, Helder; COELHO, Danilo; ALVES, Paloma Palmieri; PINHEIRO, Marina; ASTOLFI, Roberta; MARQUES, David; REIS, Milena; MERIAN, Filipe. Atlas da Violência 
2018. Rio de Janeiro: IPEA e FBSP, 2018b. 93p. Disponível em: http://www.ipea.gov.br/atlasviolencia/download/9/atlas-2018. Acesso em: 20 jan. 2019.

DAGA, Bianca. Aluno é apreendido e expulso de escola em MT após dar soco em professor, 2018. Disponível em: https://noticias.uol.com.br/cotidiano/ultimasnoticias/2018/06/13/aluno-e-apreendido-e-expulso-de-escola-no-mt-apos-dar-soco-emprofessor.htm. Acesso em: 02 ago. 2018.

DEAN, James. Projeto 'Escola Segura' da Polícia Militar é implantado na Escola Darcy Ribeiro em Guarantã do Norte, 2018. Disponível em:

http://www.amplitudenews.com.br/noticia/3389/projeto-escola-segura-da-policia-militar-eimplantado-na-escola-darcy-ribeiro-em-guaranta-do-norte. Acesso em: 01 jul. 2018.

DEEPASK. Taxa de homicídios: Veja número de assassinatos por cidade do Brasil Pesquisa mostra o número de pessoas assassinadas e a taxa de mortalidade per capita (por 100 mil habitantes) por faixa etária e cor declarada por município do país, 2013. Disponível em: http://www.deepask.com/goes?page=Confira-a-taxa-de-homicidios-no-seumunicipio. Acesso em: 07 jul. 2018.

DURKHEIM, Émile. Educação moral. Petrópolis: Editora Vozes, 2008.

FIGUEIRA, Kátia Cristina Nascimento. Forças armadas e educação: O Colégio militar de Campo Grande - MS (1993-2010). 2011. 236 f. São Carlos: Tese (Doutorado em Educação) - Universidade Federal de São Carlos, São Carlos/SP: UFSCar, 2011. Disponível em: https://repositorio.ufscar.br/bitstream/handle/ufscar/7280/TeseKCNF.pdf?sequence=1\&isAllo wed=y. Acesso em: 20 nov. 2018.

FOLHA DE SÃO PAULO. Confira a posição de sua escola no ranking nacional do Enem de 2016, 2017. Disponível em: https://www1.folha.uol.com.br/educacao/2017/12/1942488confira-a-posicao-de-sua-escola-no-ranking-nacional-do-enem-de-2016.shtml. Acesso em: 02 ago. 2018.

GAUCHAZH. Tire dúvidas sobre o Programa das Escolas Cívico-Militares, proposta de decreto assinado por Bolsonaro, 2019. Disponível em:

https://gauchazh.clicrbs.com.br/educacao-e-emprego/noticia/2019/09/tire-duvidas-sobre-oprograma-das-escolas-civico-militares-proposta-de-decreto-assinado-por-bolsonarock06ve4if02sq0115g3ipyfa8.html. Acesso em: 03 abr. 2020.

G1 - GLOBO.COM. Lei prevê punição à família de aluno que agredir professor em MT, 2017. Disponível em: http://g1.globo.com/mato-grosso/noticia/2017/01/lei-preve-punicaofamilia-de-aluno-que-agredir-professor-em-mt.html. Acesso em: 08 ago. 2018.

GONÇALVES, Luiz Alberto Oliveira; SPOSITO, Marilia Pontes. Iniciativas públicas de redução da violência escolar no Brasil. Cadernos de pesquisa, n. 115, p. 101-138, 2002. Disponível em: http://www.scielo.br/pdf/cp/n115/a04n115.pdf. Acessado em: 16 set. 2018.

GUIMARÃES, Paula Cristina Pereira. Os novos modelos de gestão militarizadas das escolas estaduais de Goiás. In: SIMPÓSIO DE HISTÓRIA NACIONAL, 29, 2017, Brasília. Anais... Brasília: UNB, 2017. p. 1-16. Disponível em: 
https://www.snh2017.anpuh.org/resources/anais/54/1502846486_ARQUIVO_TRABALHO_ COMPLETO_ANPUH_Paula_2017(1).pdf. Acesso em: 20 nov. 2018.

HILÁRIO, Gloriete Marques Alves; CONCEIÇÃO, Daniela Aparecida da. A importância do colégio militar para a formação do aluno cidadão na cidade de Arraias - TO. In: SIMPÓSIO ESTADUAL DA INICIATIVA EDUCAÇÃO, POBREZA E DESIGUALDADE SOCIAL, 1 e SEMINÁRIO DE PESQUISA EM EDUCAÇÃO, POBREZA E DESIGUALDADE

SOCIAL, 4, 2017, Palmas. Anais.... Palmas/TO: UFT campus de Palmas, 2017. p. 276-279. Disponível em: https://repositorio.uft.edu.br/bitstream/11612/1101/1/ANAIS\%20\%20I\%20SIMP\%C3\%93SIO\%20e\%20IV\%20Semin\%C3\%A1rio\%20EPDS\%20\%20\%20VOLUME\%201.pdf. Acesso em: 20 nov. 2018.

ITTELSON, William H.; PROSHANSKY, Harold M.; RIVLIN, Leanne G.; WINKEL, Gary H. An introduction to Environmental Psychology. Nova York: Holt, Rinehart \& Winston, 1974.

LIBERAL, Edson Ferreira; AIRES, Roberto Tschoepke; AIRES, Mariana Tschoepke; OSÓRIO, Ana Carla de Albuquerque. Escola segura. Jornal de Pediatria, v. 81, n. 5, p. 15563, 2005. Disponível em: http://www.scielo.br/pdf/jped/v81n5s0/v81n5Sa05.pdf. Acessado em: 16 set. 2018.

LIMA, Leidieli. Devido aumento na violência, governador determina operação da Rotam em Guarantã, 2017. Disponível em: https://olharcidade.com.br/noticia/9872/devidoaumento-na-violencia--governador-determina-operacao-da-rotam-em-guaranta. Acesso em: 05 out. 2018.

MALTA, Deborah Carvalho; SOUZA, Edinilsa Ramos de; SILVA, Marta Maria Alves da; SILVA, Carlos dos Santos; ANDREAZZI, Marco Antonio Ratzsch de; CRESPO, Claudio; MASCARENHAS, Márcio Dênis Medeiros; PORTO, Denise Lopes; FIGUEROA, Alba Lucy Giraldo; MORAES NETO, Otaliba Libânio de; PENNA, Gerson de Oliveira. Vivência de violência entre escolares brasileiros: resultados da Pesquisa Nacional de Saúde do Escolar (PeNSE). Ciência \& Saúde Coletiva, v. 15, p. 3053-3063, 2010. Disponível em: http://www.scielo.br/pdf/csc/v15s2/a10v15s2.pdf. Acessado em: 16 set. 2018.

MÜLLER, Bruno Raphael. Ordem em meio ao caos: escolas militares ganham espaço com bons resultados, 2017. Disponível em: https://www.gazetadopovo.com.br/educacao/ordemem-meio-ao-caos-escolas-militares-ganham-espaco-com-bons-resultados8mvefin96no0oydxmdkgaqreh. Acesso em: 02 jul. 2018.

NASCIMENTO, Dany. Programa 'Escola Segura, Família Forte' atende 60 escolas na Capital, 2017. Disponível em: http://www.topmidianews.com.br/cidade-morena/sem-fotoprograma-escola-segura-familia-forte-atende-60-escolas-na/81884/. Acesso em: 02 jul. 2018.

NEVES, Luiza Gonzaga Pereira das. Decreto institui Programa Escola Segura - Notícias SEDUC, 2018. Disponível em:

http://www.mt.gov.br/web/seduc/noticias?p_p_id=101_INSTANCE_dhm5m2e1mY9d\&p_p_ $\underline{\text { lifecycle }=0 \& p \_p \_s t a t e=\text { normal } \& p \_p \_1 \& p \_p \_c o l \_p o s=2 \& p \_p \_c o l \_c o u n t=3 \& \_101 \_ \text {INSTAN }}$ CE_dhm5m2e1mY9d_struts_action=\%. Acesso em: 05 jul. 2018. 
PAULA e SILVA, Joyce Mary Adam de; SALLES, Leila Maria Ferreira. A violência na escola: abordagens teóricas e propostas de prevenção. Educar em Revista, Curitiba, Brasil, n. especial 2, p. 217-232, 2010. Disponível em: http://www.scielo.br/pdf/er/nspe2/13.pdf. Acessado em: 16 set. 2018.

PAULO, Anderson. Projeto Escola segura será implantada em mais uma escola de Guarantã do Norte, 2018. Disponível em:

http://www.guarantanews.com.br/Noticias/Guaranta-do-norte/Projeto-escola-segura-seraimplantada-em-mais-uma-escola-de-guaranta-do-norte/. Acesso em: 05 jul. 2018.

PMSB - Guarantã do Norte/MT. Plano Municipal de Saneamento Básico. Volume I: Considerações iniciais, 2016. 63p. Disponível em:

https://www.guarantadonorte.mt.gov.br/fotos_institucional/87.pdf. Acesso em: 30 jan. 2019.

POLÍCIA MILITAR. Estado de Mato Grosso. Ementa disciplinar: Projeto Escola Segura da Polícia Militar. Guarantã do Norte, MT: PMMT, 2018.

QEDU. Guarantã do Norte: Ideb 2015 por escolas, 2016. Disponível em:

https://www.qedu.org.br/cidade/101-guaranta-do-norte/ideb/ideb-por-escolas. Acesso em: 21 ago. 2018.

QEDU. Resultado do Enem por escola em Guarantã do Norte - Veja as médias das escolas do município em redação e demais áreas do conhecimento avaliadas pelo Enem 2017, 2018. Disponível em: http://www.qedu.org.br/cidade/101-guaranta-do-norte/enem. Acesso em: 21 ago. 2018.

QEDU. Resultado do Enem por escola em Guarantã do Norte - Veja as médias das escolas do município em redação e demais áreas do conhecimento avaliadas pelo Enem 2018, 2019. Disponível em: https://www.qedu.org.br/cidade/101-guaranta-do-norte/enem. Acesso em: 20 fev. 2019.

R CORE TEAM. R: A language and environment for statistical computing. Austria, Vienna: R Foundation for Statistical Computing, 2019. Disponível em: https://www.R-project.org/. Acesso em: 01 jul, 2019.

RIVLIN, Leanne G. Olhando o passado e o futuro: revendo pressupostos sobre as interrelações pessoa-ambiente. Estudos de Psicologia, v. 8, n. 2, p. 215-220, 2003.

Disponível em: http://www.scielo.br/pdf/epsic/v8n2/19037.pdf. Acessado em: 16 set. 2018.

SAMPAIO, Cristiane. Como funcionam as escolas militarizadas que o governo Bolsonaro vai financiar, 2019. Disponível em: https://www.brasildefato.com.br/2019/11/21/como-

funcionam-as-escolas-militarizadas-que-governo-bolsonaro-vai-financiar. Acesso em: 03 abr. 2020.

SILVA, Juacy da. Violência nas escolas, 2018. Disponível em:

http://www.gazetadigital.com.br/colunas-e-opiniao/colunas-e-artigos/violencia-nasescolas/532582. Acesso em: 20 jan. 2019.

SILVA, Ana Claudia da.; MANICA, Fábio Raul; SOUZA, Mizael Pereira; SILVA, Ricardo Gonçalves da. Projeto Escola Segura: estudo no município de Guarantã do Norte - MT. 
2018. 17 f. Guarantã do Norte: Monografia (Especialização em Gestão Pública) - Instituto Federal de Educação, Ciência e Tecnologia de Mato Grosso - campus Várzea Grande, Guarantã do Norte/MT, 2018. Recebido via e-mail direto com o autor em 21 jan. 2019.

SÓ ESCOLA. AGORA É LEI! Família de aluno que agredir professor será responsabilizada, 2017. Disponível em: https://www.soescola.com/2017/04/agora-e-leifamilia-de-aluno-que-agredir-professor-sera-resposabilizada.html. Acesso em: 30 ago. 2018.

SÓ NOTÍCIAS. Violência nas escolas em Mato Grosso cresce 54\%, 2017. Disponível em: https://www.sonoticias.com.br/policia/violencia-nas-escolas-em-mato-grosso-cresce-54/. Acesso em: 20 jan. 2019.

SOUZA, Kátia Ovídia José de. Violência em escolas públicas e a promoção da saúde: relatos e diálogos com alunos e professores. Revista Brasileira em Promoção da Saúde, v. 25, n. 1, p. 71-79, 2012. Disponível em: https://periodicos.unifor.br/RBPS/article/view/2213/2434. Acessado em: 15 set. 2018.

SPOSITO, Marilia Pontes. Um breve balanço da pesquisa sobre violência escolar no Brasil. Revista Educação e Pesquisa, São Paulo, v. 27, n. 1, p. 87-103, jan./jun., 2001. Disponível em: http://www.scielo.br/pdf/ep/v27n1/a07v27n1.pdf. Acessado em: 15 set. 2018.

STELKO-PEREIRA, Ana Carina; WILLIAMS, Lúcia Cavalcanti de Albuquerque. Reflexões sobre o conceito de violência escolar e a busca por uma definição abrangente. Temas em psicologia, v. 18, n. 1, p. 45-55, 2010. Disponível em: http://pepsic.bvsalud.org/pdf/tp/v18n1/v18n1a05.pdf. Acessado em: 15 set. 2018.

VELHO, Gilberto. Violência, reciprocidade e desigualdade. In: VELHO, Gilberto; ALVITO, Marcos. (Orgs.). Cidadania e violência. 2. ed. Rio de Janeiro: Editoras UFRJ/FGV, 2000. p. $11-25$.

Recebido em: 28 de fevereiro de 2020 . Aprovado em: 15 de abril de 2020. 